\title{
A series of four transcatheter aortic valve replacement in failed Perceval valves
}

\author{
Martin Misfeld ${ }^{1,2}$, Mohamed Abdel-Wahab ${ }^{3}$, Holger Thiele ${ }^{3}$, Michael A. Borger ${ }^{1}$, David Holzhey ${ }^{1}$ \\ ${ }^{1}$ University Clinic of Cardiac Surgery, Leipzig Heart Center, Leipzig, Germany; ${ }^{2}$ Department of Cardiothoracic Surgery, Royal Prince Alfred \\ Hospital, Sydney, Australia; ${ }^{3}$ Clinic of Cardiology, Leipzig Heart Center, Leipzig, Germany \\ Correspondence to: Martin Misfeld. University Clinic of Cardiac Surgery, Leipzig Heart Center, Struempellstrasse 39, 04289 Leipzig, Germany. \\ Email: martinmisfeld@yahoo.com.
}

\begin{abstract}
In recent years, sutureless valves (SV) and rapid deployment valves (RDVs) have become interesting aortic valve substitutes, especially in minimally invasive aortic valve surgery, as they reduce cardio-pulmonary bypass and cross-clamp times. There are two valve types available, the sutureless Perceval and the rapid deployment Intuity valve prosthesis. When these valves fail, besides surgical re-replacement, the valvein-valve concept has been reported in a small series of case reports. Our own experience includes four cases of failed Perceval valves, in which a balloon-expandable transcatheter valve was implanted in three patients, and a self-expanding transcatheter valve was implanted in a fourth patient. Here, we present these four cases with a focus on the specific valve design of the Perceval valve, as well as on important technical aspects. All cases were performed successfully with clinical improvement. Transcatheter aortic valve replacement (TAVR) as a valve-in-valve concept seems to be a valuable option in selected patients with failed sutureless or RDVs.
\end{abstract}

Keywords: Transcatheter aortic valve replacement (TAVR); sutureless valves (SV); aortic valve

Submitted Mar 27, 2020. Accepted for publication Jun 24, 2020.

doi: 10.21037/acs-2020-surd-20

View this article at: http://dx.doi.org/10.21037/acs-2020-surd-20

\section{Introduction}

Since their introduction, sutureless valves (SV) and rapid deployment valves (RDVs) have been shown to significantly reduce cardio-pulmonary bypass and crossclamp time compared to conventional aortic valve replacement $(1,2)$. This is one reason why these valve substitutes have been used, especially in minimally invasive aortic valve surgery. As with conventional tissue valve substitutes, SV and RDV will fail over time. In addition to surgical re-replacement, transcatheter aortic valve replacement (TAVR) as a valve-in-valve $(\mathrm{V}-\mathrm{i}-\mathrm{V})$ concept may be a valid option in degenerated SV and RDV. In this context, knowledge of specific valve features of these valve substitutes is essential. This manuscript will describe four cases of a failed Perceval valve, treated with the $\mathrm{V}-\mathrm{i}-\mathrm{V}$ concept.

\section{Available SV and RDV}

The first sutureless heart valve was designed by GJ Magovern and HW Cromie in the early $60 \mathrm{~s}$ (3). The sutureless valve concept experienced a renaissance by the introduction of the $3 \mathrm{~F}$ Enable sutureless valve $(3 \mathrm{~F}$ Therapeutics, Lake Forest, CA, USA) in 2003 (4), followed by the sutureless Perceval valve (LivaNova, London, $\mathrm{UK}$ ) and the rapid deployment Intuity valve (Edwards Lifescience, Irvine, CA, USA).

As the $3 \mathrm{~F}$ Enable valve is off the market, the two available valve substitutes used today are the Perceval and the Intuity valves. The latter is a RDV, as three guiding sutures for positioning the valve are tied after the valve has been deployed and anchored with a balloon-expandable frame in the sub-annular position. The Perceval valve is a truly suture-less valve. It is composed of a bovine pericardial 


\begin{tabular}{l}
$\begin{array}{l}\text { Table } 1 \text { Sizes and diameters of the sutureless Perceval aortic valve } \\
\text { prosthesis (Source: https://www.accessdata.fda.gov/cdrh_docs/ } \\
\text { pdf15/P150011d.pdf) }\end{array}$ \\
\begin{tabular}{llll} 
Ref & Size & $\begin{array}{l}\text { Aortic annulus } \\
\text { diameter }[\mathrm{A}](\mathrm{mm})\end{array}$ & $\begin{array}{l}\text { Sinotubular junction } \\
\text { diameter }[\leq 1.3 \mathrm{~A}]\end{array}$ \\
\hline PVS21 & S & $19-21$ & $\leq 24.7-27.3$ \\
PVS23 & M & $21-23$ & $\leq 27.3-29.9$ \\
PVS25 & L & $23-25$ & $\leq 29.9-32.5$ \\
PVS27 & XL & $25-27$ & $\leq 32.5-35.1$
\end{tabular} \\
\hline
\end{tabular}

valve unit, mounted in a carbofilm coated frame. This frame fixes the valve at annular, sinus and sino-tubular levels.

The Perceval valve comes in four sizes: $\mathrm{S}, \mathrm{M}, \mathrm{L}$, and $\mathrm{XL}$. These sizes correspond to specific annular diameters, which are given in Table 1. It becomes clear that a $21 \mathrm{~mm}$ annulus diameter corresponds to a Perceval valve size $\mathrm{S}$ as well as size $M$.

Recent studies demonstrate that SV and RDV show very good results in different risk groups and are excellent valve substitutes, especially for the minimally invasive approach $(1,2)$.

\section{Literature overview of TAVR in SV and RDV}

To date, there are only case series that report on TAVR procedures in failed SV and RDV. To the best of our knowledge, a total number of 23 cases have been described so far $(5-21)$. This includes a previous publication by the authors (16). There is also a report of a series of $30 \mathrm{~V}-\mathrm{i}-\mathrm{V}$ procedures in SV and RDV published by Landes et al. (22). This series is part of the multicenter VIVID International Registry. It also includes five 3F Enable valves besides 24 implants in Perceval and one $\mathrm{V}-\mathrm{i}-\mathrm{V}$ in an Intuity valve. As the possibility that single case reports have been part of this registry cannot be excluded, , these 30 cases have not been simply added in numbers to the published case reports. An overview of the current literature of reported case reports and small series, excluding $3 \mathrm{~F}$ Enable valves, is given in Table 2.

In the majority of cases, a TAVR procedure was performed in failed Perceval valves. This may be related to the total number of Perceval valves implanted compared to the Intuity valve. There were various causes of failure. In the majority, structural valve deterioration (SVD) was present with combined valve stenosis and regurgitation.
Two TAVR valve types and their modifications were implanted. In thirteen cases, a balloon-expandable valve (Sapien, Sapien XT, Sapien 3; Edwards Lifescience, Irvine, CA, USA) was implanted $(5,6,8,9-11,13,16-19,21)$. In the remaining five cases, a self-expanding valve (Corevalve, Evolut R, Evolut Pro, Medtronic, Minneapolis, MN, USA) was used $(7,9,12,14,15,20)$. Both valve types have specific characteristics related to valve design and implantation technique. These characteristics have to be considered when using these TAVR valve substitutes in failed SV and RDV.

\section{Case series}

We describe a series of four cases, which in three patients a balloon-expandable Sapien 3, and in the fourth patient a self-expanding Evolut R valve was implanted in a failed sutureless Perceval valve.

\section{Case 1}

A 77-year-old female patient underwent aortic valve replacement for combined aortic valve disease with a Perceval valve size S in May 2010. Cardiovascular risk factors included arterial hypertension, dyslipidemia, and obesity. Following an unremarkable postoperative course, the patient was readmitted in March 2018 with progressive shortness of breath [New York Heart Association (NYHA) class II-III]. Investigations revealed prosthetic valve stenosis and single vessel coronary artery disease. During left heart catheterization, a significant stenosis of the left anterior descending artery was treated using a drug-eluting stent.

Transesophageal echocardiography (TEE) showed preserved left ventricular (LV) function (LV-EF 62\%), a stenotic Perceval prosthesis with a mean gradient of $54 \mathrm{mmHg}$ and an aortic valve area (AVA) of $0.6 \mathrm{~cm}^{2}$. There was also mild aortic valve regurgitation, mitral valve (MV) stenosis grade $\mathrm{I}-\mathrm{II}^{\circ}$ with annular calcification and regurgitation grade $\mathrm{I}^{\circ}$, as well as tricuspid valve (TV) regurgitation grade II $^{\circ}$.

Pre-TAVR computed tomography (CT) scan showed an annulus diameter (mean/max) of 18/21 mm and an effective diameter (area/circumference) of 19/20 mm. Further dimensions of the aortic root included a mid-sinus diameter of $25 \mathrm{~mm}$ and a sino-tubular junction of $23 \mathrm{~mm}$. The distance of coronary ostia to the annular plane was $9 \mathrm{~mm}$ to the left coronary ostium and $10 \mathrm{~mm}$ to the right coronary ostium. Peripheral vessel diameters are given in Table 3. 
Table 2 Case series and case reports of TAVR procedures in failed sutureless and rapid deployment valves

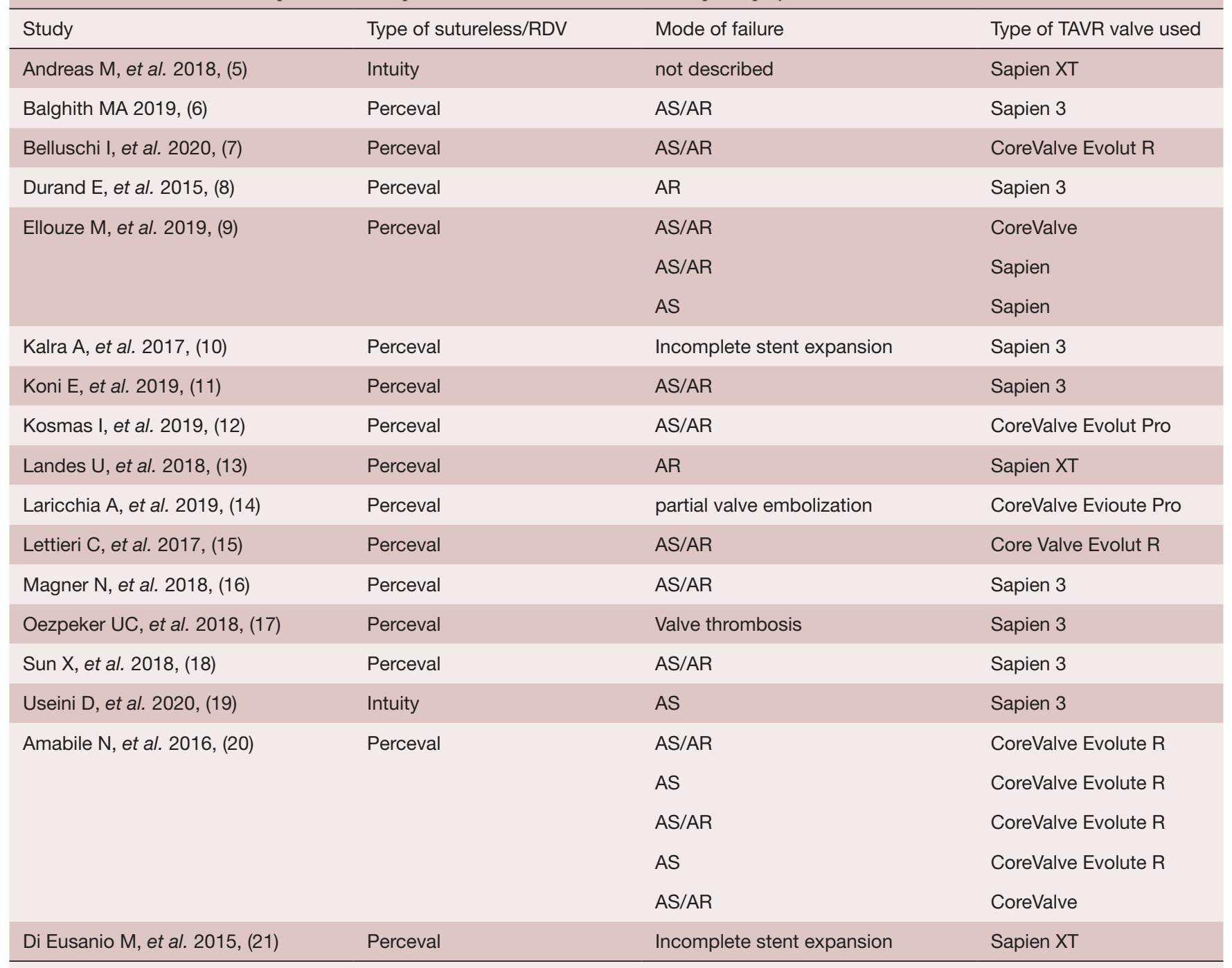

AS, aortic stenosis; AR, aortic regurgitation.

Table 3 Case 1: peripheral vessel diameters

\begin{tabular}{lll}
\hline Vessel & Right $(\mathrm{mm})$ & Left $(\mathrm{mm})$ \\
\hline Common iliac artery & 8 & 8 \\
External iliac artery & 6 & 7 \\
Femoral artery & 7 & 8 \\
\hline
\end{tabular}

\section{Technical aspects}

A $20 \mathrm{~mm}$ Sapien 3 valve was chosen for the TAVR procedure. The implantation technique followed a standardized protocol.
The TAVR was performed without any complications. Final assessment demonstrated adequate position of the TAVR valve with no relevant residual aortic regurgitation (Figure 1).

\section{Outcome}

The patient left the hybrid operation room in a hemodynamically stable condition. Postoperative transthoracic echocardiography (TTE) demonstrated normal LV function and a mean gradient across the valve of $24 \mathrm{mmHg}$. Effective orifice area (EOA) was calculated at $1.0 \mathrm{~cm}^{2}$. There was only trivial paravalvular leak. The patient was discharged on postoperative day (POD) two. 


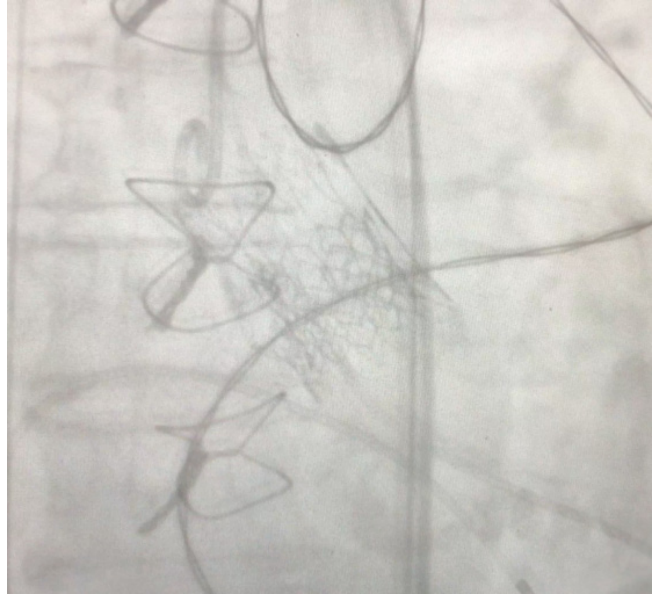

Figure 1 A $20 \mathrm{~mm}$ Sapien 3 valve is placed into a failed Perceval size $\mathrm{S}$ valve.

\begin{tabular}{lll}
\multicolumn{2}{l}{ Table 4 Case 2: peripheral vessel diameters } \\
\hline Vessel & Right $(\mathrm{mm})$ & Left $(\mathrm{mm})$ \\
\hline Common iliac artery & 10 & 9 \\
External iliac artery & 7 & 7 \\
Femoral artery & 8 & 7 \\
\hline
\end{tabular}

At 12-month follow-up, the patient showed improvement in clinical symptoms (NYHA I-II). Pressure gradients had further decreased (mean gradient $13 \mathrm{mmHg}$ ) and the EOA was measured at $1.2 \mathrm{~cm}^{2}$. There was only trivial paravalvular leakage.

\section{Case 2}

An 82 -year-old female patient was admitted with deterioration of clinical symptoms (NYHA II-III). In July 2010, she underwent aortic valve replacement with a Perceval size $L$ valve due to symptomatic aortic valve stenosis. Postoperatively, a permanent pacemaker was inserted. Her cardiovascular risk factors included arterial hypertension and dyslipidemia. Investigations revealed prosthetic valve stenosis with a mean gradient of $35 \mathrm{mmHg}$ and an AVA of $0.85 \mathrm{~cm}^{2}$. LV function was impaired with an ejection fraction of $41 \%$. There was also mild to moderate mitral $\left(\mathrm{I}-\mathrm{II} \mathrm{I}^{\circ}\right)$ and tricuspid $\left(\mathrm{II}^{\circ}\right)$ regurgitation.

A pre-procedural CT scan showed the following diameters: annulus $(\min / \max ) 24 / 26 \mathrm{~mm}$, effective 25/26 mm (area/circumference), mid-sinus $31 \mathrm{~mm}$, sino-

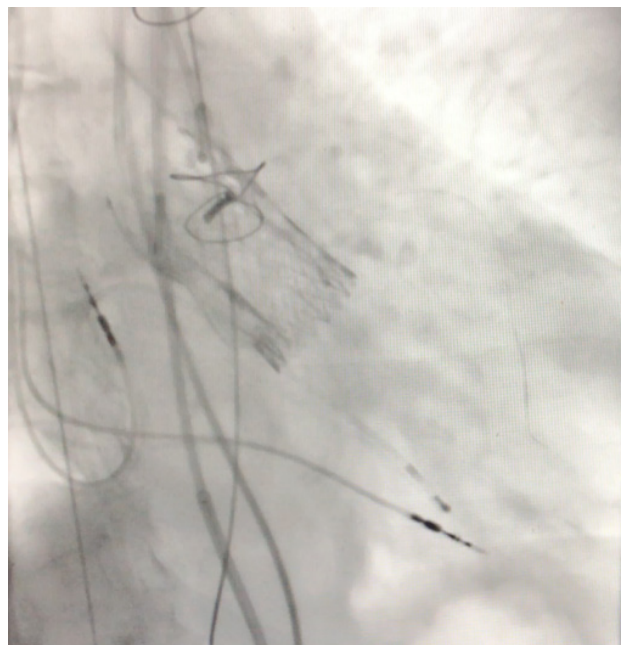

Figure 2 A 29 mm Evolut R is placed into a failed Perceval size L valve.

tubular junction $31 \mathrm{~mm}$; distance to left coronary ostium $8 \mathrm{~mm}$ and right coronary ostium $14 \mathrm{~mm}$. Peripheral vessel diameters are given in Table 4.

\section{Technical aspects}

Following a standard protocol, in this case with additional placement of a guiding wire (EBU 3.5) into the left coronary artery via the right radial artery due to the low take-off of the left coronary ostium, a $29 \mathrm{~mm}$ self-expanding Evolut R prosthesis was implanted under temporary fast ventricular pacing. Because the stent was not completely expanded, a balloon valvuloplasty using a 24 followed by a $25 \mathrm{~mm}$ balloon was performed under temporary rapid ventricular pacing.

\section{Outcome}

Figure 2 shows the final result of the implantation. The postoperative course was uneventful. On TTE, LV function had slightly improved (LV ejection fraction 47\%). Mean pressure gradient was $11 \mathrm{mmHg}$ and EOA was calculated at $1.8 \mathrm{~cm}^{2}$. There was mild residual aortic regurgitation. The patient was discharged on POD three.

At 3-month follow-up, clinical symptoms had improved (NYHA I-II'). TTE showed an LV ejection fraction of $48 \%$ and a low mean pressure gradient of max $6 \mathrm{mmHg}$ with an EOA of $1.9 \mathrm{~cm}^{2}$. There was still mild aortic regurgitation.

\section{Case 3}

A 76-year-old female patient with combined aortic 


\begin{tabular}{lll}
\multicolumn{2}{l}{ Table 5 Case 3: peripheral vessel diameters } \\
\hline Vessel & Right $(\mathrm{mm})$ & Left $(\mathrm{mm})$ \\
\hline Common iliac artery & 18 & 8 \\
External iliac artery & 6 & 7 \\
Femoral artery & 7 & 7 \\
\hline
\end{tabular}



Figure 3 A $23 \mathrm{~mm}$ Sapien 3 valve is placed into a failed Perceval size $\mathrm{S}$ valve.

valve stenosis and regurgitation underwent aortic valve replacement with a Perceval valve size S in December 2011. Cardiovascular risk factors in this case included arterial hypertension, dyslipidemia, diabetes mellitus and obesity. The patient was readmitted in April 2017 with progressive dyspnea (NYHA II-III) related to combined prosthetic valve stenosis and regurgitation.

Pre-procedural echocardiography revealed preserved LV function (ejection fraction 55\%) and combined moderate valve stenosis and moderately-severe regurgitation.

The following diameters were measured in CT scan: annulus $\mathrm{min} / \mathrm{max} ; 19 / 22 \mathrm{~mm}$, effective 20/20 mm (area/ circumference), mid-sinus $28 \mathrm{~mm}$, sino-tubular junction $22 \mathrm{~mm}$, distance to the left coronary ostium $8 \mathrm{~mm}$ and to the right coronary ostium $14 \mathrm{~mm}$. Peripheral vessel diameters are shown in Table 5.

\section{Technical aspects}

In addition to the standard protocol, a Sentinel protection device (Claret Medical, Santa Rosa, CA, USA) was placed into the innominate and the left common carotid artery. A guiding catheter and wire were also positioned into the left coronary artery due to the low take-off of the left coronary ostium. The $\mathrm{V}-\mathrm{i}-\mathrm{V}$ procedure was performed using a $23 \mathrm{~mm}$ Sapien 3 transcatheter valve.

\section{Outcome}

The final result is depicted in Figure 3. Analysis of the cerebral protection system revealed large debris in both filters. The early course was complicated by bleeding into the right groin, which was treated conservatively. On TTE, LV ejection fraction was $47 \%$, mean gradient was slightly increased $(23 \mathrm{mmHg})$, and the EOA was $1.1 \mathrm{~cm}^{2}$. There was only trivial residual aortic regurgitation. The patient was discharged on POD five.

At 3-month follow-up, this patient had also clinically improved (NYHA I-II). LV function also improved (LV ejection fraction $57 \%$ ) and mean gradient was $17 \mathrm{mmHg}$ with an EOA of $1.5 \mathrm{~cm}^{2}$. There was only trivial residual aortic regurgitation.

\section{Case 4}

The final case was an 85-year-old female patient with combined aortic valve stenosis and regurgitation. She underwent aortic valve replacement with a Perceval valve size S in January 2015. In addition to angioplasty of the left anterior descending coronary artery with a DES in November 2019, the left atrial appendage was partly closed with a Watchman FLX 24 mm Device (Boston Scientific, Marlborough, MA, USA) due to atrial fibrillation with recurrent gastro-intestinal bleeding under anticoagulation.

The patient was readmitted in December 2019 with progressive dyspnea (NYHA III-IV), related to combined prosthetic valve stenosis and regurgitation.

Pre-procedural echocardiography revealed preserved LV function (EF of 64\%) and aortic valve stenosis with max/ mean gradient of $64 / 41 \mathrm{mmHg}$ and mild aortic regurgitation.

CT scan revealed the following diameters: annulus $\mathrm{min} / \mathrm{max} 20 / 22 \mathrm{~mm}$, effective $20.7 / 20.9 \mathrm{~mm}$ (area/ circumference), mid-sinus $33 \mathrm{~mm}$, sino-tubular junction $24 \mathrm{~mm}$, distance of coronary ostia to the left coronary ostium $11 \mathrm{~mm}$ and to the right coronary ostium $13 \mathrm{~mm}$. Peripheral vessel diameters are shown in Table 6.

\section{Technical aspects}

In addition to the standard protocol, a Sentinel protection device (Claret Medical, Santa Rosa, CA, USA) was placed into the innominate and the left common carotid artery. 


\begin{tabular}{lll}
\multicolumn{2}{l}{ Table 6 Case 4: peripheral vessel diameters } \\
\hline Vessel & Right $(\mathrm{mm})$ & Left $(\mathrm{mm})$ \\
\hline Common iliac artery & 9 & 8 \\
\hline External iliac artery & 7 & 7 \\
Femoral artery & 9 & 8 \\
\hline
\end{tabular}

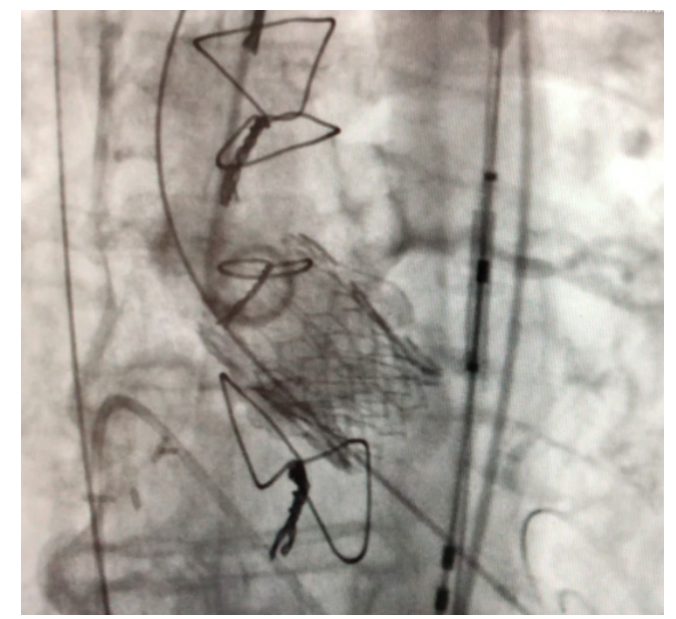

Figure 4 A $20 \mathrm{~mm}$ Sapien 3 valve is placed into a failed Perceval size $\mathrm{S}$ valve.

The $\mathrm{V}-\mathrm{i}-\mathrm{V}$ procedure was performed using a $20 \mathrm{~mm}$ Sapien 3 transcatheter valve.

\section{Outcome}

The final result is shown in Figure 4. Analysis of the cerebral protection system revealed debris in both filters. The early course was uncomplicated and the patient was discharged on POD 3.

At 3-month follow-up, this patient had also clinically improved, but still had dyspnea (NYHA II-III). LV function was normal and mean gradient across the aortic valve prosthesis was $17 \mathrm{mmHg}$ with an EOA of $1.2 \mathrm{~cm}^{2}$. There was no residual aortic regurgitation. During the last admission, an Amplatzer Vascular Plug III (St. Jude Medical Inc., MN, USA) was implanted to close the residual gap in the LAA.

\section{Case summary}

An overview of important aspects of all four cases is given in Table 7. All cases can be attributed as being technically feasible, with case 1 and case 3 being not successful according to the VARC-2 definitions (23), as mean pressure gradient was above $20 \mathrm{mmHG}$. However, clinically, all patients had improved at follow-up.

\section{Conclusions}

$\mathrm{SV}$ and RDV are popular, especially in minimally invasive aortic valve surgery. Mid-term results of valve performance are available $(1,2)$. In failed $\mathrm{SV}$ and $\mathrm{RDV}, \mathrm{V}-\mathrm{i}-\mathrm{V}$ procedures are an attractive concept, as a considerable number of patients who have received SV and RDV are elderly with several co-morbidities.

With the four cases reported here [including a previous report of one case (16)], a total number of 26 cases have been reported, in which a TAVR procedure was performed in failed SV and RDV. In addition, there is a report of 30 cases by Landes et al. (22), as part of the VIVID International Registry (22), which may represent some of the single case reports, published in the literature overview given in Table 2. In the majority of cases, TAVR was performed in sutureless Perceval valves (6-18,20,21). There are only two case reports in which a TAVR procedure was described in a failed Intuity valve $(5,19)$. We therefore cannot comment on TAVR procedures in failed Intuity valves, but in general, we would not hesitate to perform TAVR procedures in SV or RDV.

It is important to note that specific design features of both valves have to be known before a TAVR procedure can be performed. Especially with the Perceval valve, size labelling and its correlation to the annulus diameter is an important issue for adequate sizing of the TAVR valve. As in all our TAVR cases, we performed the standard preprocedural investigations. Calculations of diameters by CT scan can help to choose the right valve size. In the first case with an effective annular diameter of $19 / 20 \mathrm{~mm}$, a $20 \mathrm{~mm}$ Sapien 3 valve was chosen, in contrast to the $23 \mathrm{~mm}$ Sapien 3 valve in the third case with an effective annular diameter of $20 \mathrm{~mm}$. The reason for this remains unclear. Both cases had only a trivial residual regurgitation. Therefore, both valve sizes seem to be adequate for a size $\mathrm{S}$ Perceval valve. In the second case, with a size L Perceval valve, a $29 \mathrm{~mm}$ Evolut $\mathrm{R}$ valve was used. This demonstrates that this TAVR valve type also seems to be suitable as a $\mathrm{V}-\mathrm{i}-\mathrm{V}$ concept in failed Perceval valves. It also demonstrates that these pressure gradients with this device in a Perceval size $L$ valve were much more favorable compared to the Sapien 3 valve in smaller sizes.

Due to the specific valve design of the Perceval valve 


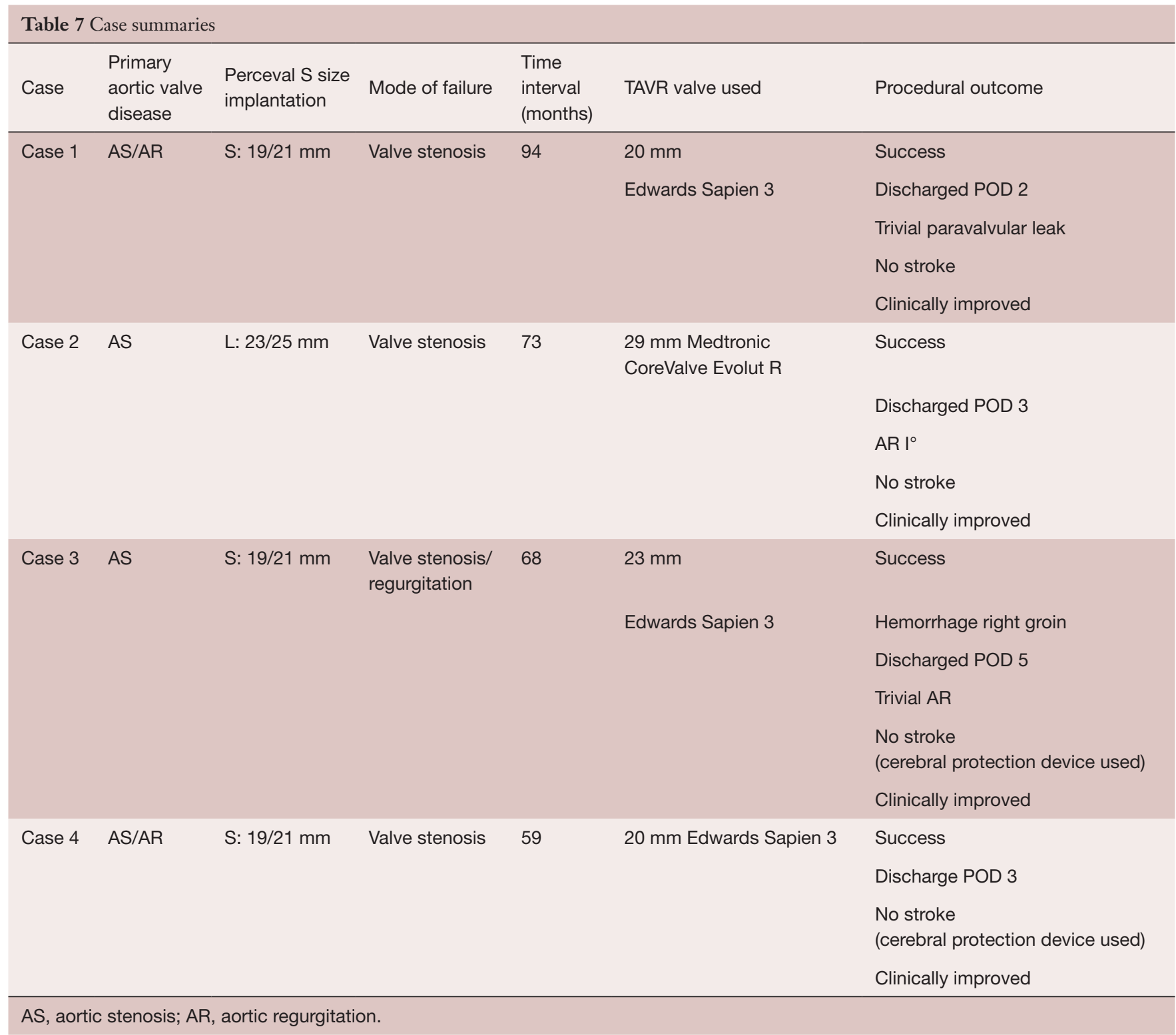

with the frame covering both coronary ostia, liberal use of safety guiding wires in the coronary ostia should be used, especially if the left coronary ostium has a low take-off. It can be challenging to insert a wire into the coronary ostia through two frames, one of the Perceval and the other of the TAVR valve, covering each other.

It needs to be proven if the double cage of a Sapien or a CoreValve substitute above a Perceval valve are protective with regard to coronary ostia occlusion. However, with $\mathrm{V}-\mathrm{i}-\mathrm{V}$ procedures in an Intuity valve which has the same design as a standard stented bioprosthesis, the risk of coronary ostia obstruction should be the same as in $\mathrm{V}-\mathrm{i}-\mathrm{V}$ procedures in conventional stented bioprostheses.

Interestingly, we saw pieces of debris in the third and fourth case where we used a cerebral protection device. This has been shown before by Schmidt et al. (24). They demonstrated that in all patients undergoing $\mathrm{V}-\mathrm{i}-\mathrm{V}$ procedures, debris could be found in either one or both of the protection filters. In addition, two further studies demonstrated that lesion volume on post-TAVR magnetic resonance imaging was reduced by the use of cerebral protection devices $(25,26)$. Addressing these findings, it is 
our strategy now to use cerebral protection devices in all $\mathrm{V}-\mathrm{i}-\mathrm{V}$ procedures.

Taking specific and patient related prosthetic valve related factors into account, the $\mathrm{V}-\mathrm{i}-\mathrm{V}$ concept for treating failed SV and RDV with TAVR remains a valuable option.

\section{Acknowledgments}

None.

\section{Footnote}

Conflicts of Interest: The authors have no conflicts of interest to declare.

Open Access Statement: This is an Open Access article distributed in accordance with the Creative Commons Attribution-NonCommercial-NoDerivs 4.0 International License (CC BY-NC-ND 4.0), which permits the noncommercial replication and distribution of the article with the strict proviso that no changes or edits are made and the original work is properly cited (including links to both the formal publication through the relevant DOI and the license). See: https://creativecommons.org/licenses/by-nc-nd/4.0/.

\section{References}

1. Berretta P, Andreas M, Carrel TP, et al. Minimally invasive aortic valve replacement with sutureless and rapid deployment valves: a report from an international registry (Sutureless and Rapid Deployment International Registry). Eur J Cardiothorac Surg 2019;56:793-9.

2. Santarpino G, Berretta P, Fischlein T, et al. Operative outcome of patients at low, intermediate, high and "very high" surgical risk undergoing isolated aortic valve replacement with sutureless and rapid deployment prostheses: results of the SURD-IR registry. Eur J Cardiothorac Surg 2019;56:38-43.

3. Magovern GJ, Cromie HW. Sutureless heart valves. J Thorac Cardiovasc Surg 1963;46:726-36.

4. Mueller XM, von Segesser LK. A new equine pericardial stentless valve. J Thorac Cardiovasc Surg 2003;125:1405-11.

5. Andreas M, Coti J, Laufer G, et al. Valve-in valve transcatheter aortic valve implantation into a novel, sutureless bioprosthesis: technical considerations. Eurointervention 2018;13:1902-3.

6. Balghith MA. Degenerated sutureless Perceval with (paravalvular leak and AS) treated by valve in valve using
S3 Edward Valve. Heart Views 2019;20:166-9.

7. Belluschi I, Buzzatti N, Blasio A, et al. Self-expanding valve-in-valve treatment for failing sutureless aortic bioprosthesis. J Card Surg 2020;35:477-9.

8. Durand E, Tron C, Eltchaninoff H. Emergency transcatheter aortic valve implantation for acute and early failure of sutureless Perceval aortic valve. Can J Cardiol 2015;31:1204.e13-5.

9. Ellouze M, Mazine A, Carrier M, et al. Sutureless and Transcatheter Aortic Valve Replacement: When Rivals Become Allies. Semin Thorac Cardiovasc Surg 2019. doi: 10.1053/j.semtcvs.2019.07.003.

10. Kalra A, Reyes M, Yang EY, et al. Transcatheter aortic valve replacement for Perceval sutureless aortic valve failure. J Invasive Cardiol 2017;29:E65-6.

11. Koni E, Trianni G, Ravani M, et al. Bailout ballon predilatation and buddy wire technique for crossing a degenerated sutureless Perceval bioprosthesis with Sapien 3 Ultra Device in a transcatheter valve-in-valve intervention. Cardiovasc Revasc Med 2019;20:75-8.

12. Kosmas I, Iakovou I, Leontiadis E, et al. The first transcatheter valve-in-valve implantation of a selfexpandable valve for the treatment of a degenerated sutureless aortic bioprosthesis. Hellenic J Cardiol 2020;61:49-50.

13. Landes U, Sagie A, Kornowski R. Transcatheter aortic valve implantation in degenerative sutureless Perceval aortic bioprosthesis. Catheter Cardiovasc Interv 2018;91:1000-4.

14. Laricchia A, Mangnieri A, Colombo A, et al. Perceval sutureless valve migration treated by valve-in-valve with a CorValve Evolut Pro. Catheter Cardiovasc Interv 2020;96:225-7.

15. Lettieri C, Romano M, Camurri N, et al. Transcatheter Valve-In-Valve Implantation in a Patient With a Degenerative Sutureless Aortic Bioprosthesis: Case Report and Literature Review. G Ital Cardiol (Rome) 2017;18:18S-21S.

16. Mangner N, Holzhey D, Misfeld M, et al. Treatment of a degenerated sutureless Sorin Perceval valve using an Edwards Sapien 3. Interact Cardiovasc Thorac Surg 2018;26:364-6.

17. Oezpeker UC, Feuchtner G, Bonaros N. Cusp thrombosis of a self-expandable aortic valve treated by valve-in-valve transcatheter aortic valve implantation procedure: case report. Eur Heart J Case Rep 2018;2:yty117.

18. Sun X, Song Z, Soffer D, et al. Transcatheter aortic valvein-valve implantation for early failure of sutureless aortic 
bioprosthesis. J Card Surg 2018;33:172-5.

19. Useini D, Belili B, Schlömicher M, et al. Valve-in-valve after Edwards Intuity valve implantation in small aortic annulus. Ann Thorac Surg 2020. [Epub ahead of print].

20. Amabile N, Zannis K, Veugeois A, et al. Early outcome of degenerated seld-expandable sutureless aortic prostheses treated with transcatheter valve implantation: A pilot series. J Thorac Cardiovasc Surg 2016;152:1635-7.

21. Di Eusanio M, Saia F, Pellicciari G, et al. In the era of the valve-in-valve: is transcatheter aortic valve implantation (TAVI) in sutureless valves feasible? Ann cardiothorac Surg 2015;4:214-7.

22. Landes U, Dvir D, Schoels W, et al. Transcatheter aortic valve-in-valve implantation in degenerative rapid deployment bioprostheses. EuroIntervention 2019;15:37-43.

23. Kappetein AP, Head SJ, Genereux P, et al. Updated standardized endpoint definitions for transcatheter

Cite this article as: Misfeld $M$, Abdel-Wahab M, Thiele H, Borger MA, Holzhey D. A series of four transcatheter aortic valve replacement in failed Perceval valves. Ann Cardiothorac Surg 2020;9(4):280-288. doi: 10.21037/acs-2020-surd-20 aortic valve implantation: the Valve Academic Research Consortium-2 consensus document 8VARC-2). Eur J Cardiothorac Surg 2012;42:S45-60.

24. Schmidt, T, Schlüter M, Alessandrini H, et al. Histology of debris captured by cerebral protection system during transcatheter valve-in-valve implantation. Heart 2016;102:1573-80.

25. Van Mieghem NM, van Gils L, Ahmad H, et al. Filterbased cerebral embolic protection with transcatheter aortic valve implantation: the randomized MISTRAL-C trial. EuroIntervention 2016;12:499-507.

26. Haussig S, Magner, N, Dwyer MG, et al. Effect of a cerebral protection device on brain lesions following transcatheter aortic valve implantation in patients with severe aortic stenosis. The CLEAN-TAVI Randomized Clinical Trial. JAMA 2016;316:592-601. 